\title{
Computer simulation of vortex combustion processes in fire-tube boilers
}

\author{
Sergei A. Khaustova ${ }^{\mathrm{a}}$, Alexander S. Zavorin, Konstantin V. Buvakov, Lidiya D. Kudryashova \\ and Anastasiya V. Tshelkunova
}

National Research Tomsk Polytechnic University, 634050 Tomsk, Russia

\begin{abstract}
The article describes computer simulation of the turbulent methane-air combustion in a fire-tube boiler furnace. Computer simulations performed for variants of once-through fire-tube furnace and reversive flame furnace. Options with various twist parameters of the fuel-air jet were examined. The flame structure has been determined computationally, contours of average speed, temperature and concentrations have been acquired. The results of calculations are presented in graphical form. Dependence of construction characteristics on vortex aerodynamic parameters was estimated. Turbulent combustion of natural gas in the reverse flame of fire-tube boiler was studied by means of the ANSYS Fluent 12.1.4 engineering simulation software.
\end{abstract}

\section{Introduction}

The main task of designing rational boiler furnaces is to ensure the possibility of mixing regulation, and consequently the dimensions of the flame control. Thus it is necessary to consider not only the mixing processes within the burner but mixing in the vortices of furnace volume also should be estimated. Moreover appropriate organization of furnace aerodynamics in fire-tube boilers can influence burning stability, lead to required flue gas temperatures and reduce the level of toxic emission into environment. Therefore, improving aerodynamic characteristics of the fire tube is a main task in elaborating the firetube boiler construction. It is particularly relevant to the dead-end furnace types where aerodynamics of the reverse flame includes interaction between the straight-through flow and reversed flow [1, 2]. Low inlet pressure at the furnace entrance provokes formation of scorching furnace gas vortexes, circulating to the burner slot. Thereby, an area for recirculation of some combustion products toward the burner root occurs. Spatially it is a single vortex in a toroidal form whose rotation axis coincides with the burner's central axis.

The toroidal vortex is a phenomenon in which an area of a rotating liquid or gas moves through the same area of the fluid or gas and the flow pattern takes the form of a toroid. Vortex rings were first mathematically analyzed by the German physicist Hermann von Helmholtz in his paper "Ueber Integrale der hydrodynamischen Gleichungen, welche den Wirbelbewegungen entsprechen" [3]. In boiler furnace vortex ring is created by the impact of a rapidly moving gaseous fuel-air jet (fluid A) in a stationary

\footnotetext{
${ }^{a}$ Corresponding author: khaustovsa@tpu.ru
}

This is an Open Access article distributed under the terms of the Creative Commons Attribution License 4.0, which permits unrestricted use, distribution, and reproduction in any medium, provided the original work is properly cited. 

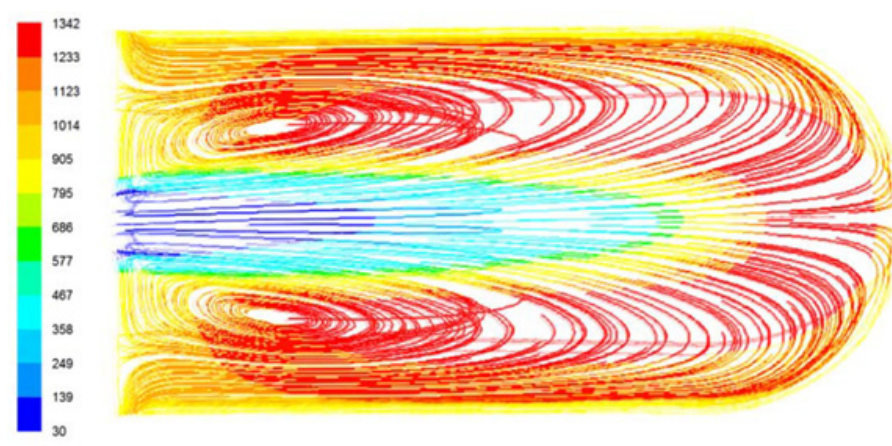

(a)

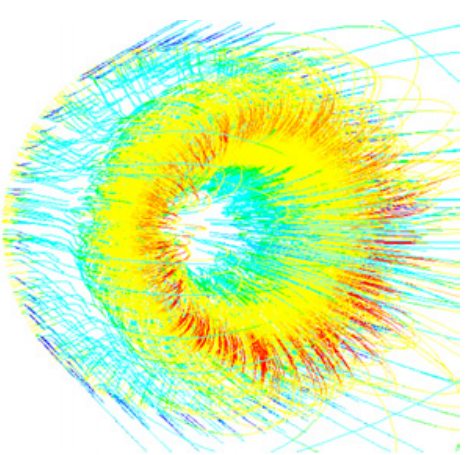

(b)

Figure 1. Pathlines in the reversive flame colored by the temperature (a) and spatial 3d-image of recirculation vortex (b).

mass of combustion products (fluid B). Viscous friction at the interface between these two fluids causes motion of fluid A to slow down. Layers of the mass B bend around mass A and go back to the burner slot where they are included in flow A, eventually forming the poloidal fluxes of a vortex ring. Full-scale multiple-factor experimental research of described three-dimensional vortical turbulent combustion is quite expensive. Therefore, nowadays computer simulation with the use of wide approved application packages is used to research furnace aerodynamics [4]. For example, burning turbulent vortex flow was simulated in $[1,2,5]$.

This paper is aimed at computer simulation of the turbulent methane-air combustion in a firetube boiler. The flame structure has been determined computationally, contours of average speed, temperature and concentrations have been acquired. The subject of studying: complex of characteristics with space-time fields of the aerodynamic structure of the vortices, range and aperture angle of the flame. Dependence of construction characteristics on vortex aerodynamic parameters is also estimated. Turbulent combustion of natural gas in the reverse flame of fire-tube boiler was studied by means of the ANSYS Fluent 12.1.4 engineering simulation software. The following processes were simulated through the finite-element method: kinetic and turbulent reactions, turbulence, and heat exchange. The gas-phase was simulated according to the Euler's approximation. Aerodynamic calculations were performed using laws of flow continuity and energy conservation. The radiant heat exchange calculation was conducted by the method of spherical harmonics in first approximation (P1-model). Differential equations used by the given radiative heat transfer model are presented in [6].

\section{Eddy currents in the reversive flame}

In papers $[2,7]$ is shown that low inlet pressure at the dead-end furnace entrance provokes formation of scorching furnace gas vortexes, circulating to the burner slot (Fig. 1). So in reversive flame between the two coaxial counter flows recirculation vortex is observed. The swirling area is bounded by stream of fuel-air mixture, on the one hand, and the reverse flow on the other.

In the emerging vortex kinetic energy of turbulence reaches its maximum causing high burning rate on its narrow boundaries [7]. As the result vortex is filled by combustion products (carbon dioxide, nitrogen and its oxides, water vapor) with temperatures close to the flame temperature. For this reason, the new fuel-air mixture, contacting with vortex flue gases, almost immediately heats up by convection and heat conduction. Described vortical aerodynamics of reversive flame intensifies burning and enables the process at a low air excess, but increases aerodynamic furnace resistance. Pressure loss in this case is 


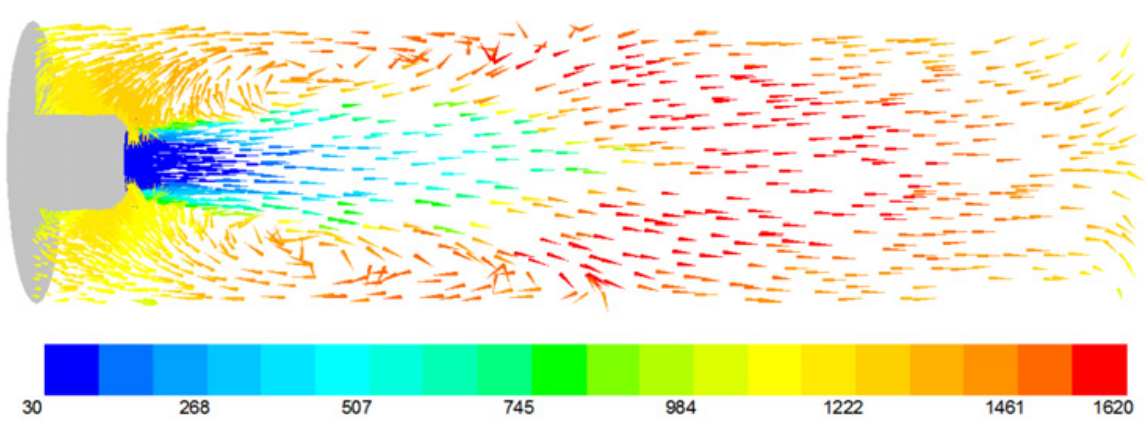

Figure 2. Motion vectors in straight-flow fire-tube furnace with color indexation according to the temperature.

consumed by vortex shedding associated with flow separation from the walls, i.e. to maintain continuous rotational motion of gaseous masses with their constant updating.

Since the combustion products are drawn into the recirculation zone directly from the reaction zone, the heat from the flame $\left(\mathrm{Q}_{\mathrm{r}}\right)$ can be calculated as the multiplication of volume fraction of the recirculation ( $r$ ) by enthalpy $\mathrm{H}_{\text {flame }}$ of the flame: $\mathrm{Q}_{\mathrm{r}}=\mathrm{r} \cdot \mathrm{H}_{\text {flame }}, \mathrm{kJ} / \mathrm{m}^{3}$. The portion of recirculation heat, perceived by air-fuel mixture may be determined as: $\mathrm{Q}=\mathrm{Q}_{\mathrm{r}}-\mathrm{r} \cdot \mathrm{H}_{\text {out }}, \mathrm{kJ} / \mathrm{m}^{3}$, where $\mathrm{H}_{\text {out }}-$ is a enthalpy of the flue gases leaving the furnace.

\section{Eddy currents in the straight-flow flame}

The aerodynamic structure of vortex in straight-flow flame differs from reversive one. In straight-flow furnaces vortex motion also occurs, but the swirling area is bounded by jet only on the one side, another side is bounded by the wall. On the axial plane of the fire tube, this zone also looks like elliptical swirls along both sides of the flame (Fig. 2), but spatially it is a quasi-stationary toroidal vortex whose rotation coaxial with the burner's central axis. There is no intensive mixing of recirculated gases with air-fuel mixture due to the high density difference. The amount of combustion products in the vortex is quasi-permanent, because substance does not enter or leave the vortex.

\section{Eddy currents in the twisted flow}

Another known way of creating vortical aerodynamics in furnace volume is using of swirl burners. Twisted jet generated by such burners also causes burning intensification and enables the process at a low air excess, but additionally increases aerodynamic resistance. In twisted flow the law of inertia is manifested and centrifugal force arises, acting on a new fuel-air jet.

With increasing of flow twist (Fig. 3) the zone of maximum heat release is getting closer to the front of the boiler. Inflammation in this case is intensified and flame range decreases. Vortex motion acquires a tangential velocity component, and as a result gas jets move in complicated spiral trajectories.

Computer-aided simulation shows that increasing of twist parameter causes the growth of temperatures in the furnace volume. The distribution of heat release becomes less uniform due to the fact that position of the flame core is shifted to the front of the boiler. On the one hand higher level of combustion temperatures causes better radiation heat absorption. But on another hand this applies only to the once-through furnace design. Authors of paper [1] show that in the reversive fire-tube furnace with whirl burner flame core shifted to the front of the boiler, where exit from the furnace is situated, increasing the temperature of exhaust gases and reducing heat absorption. At the same time, high values 


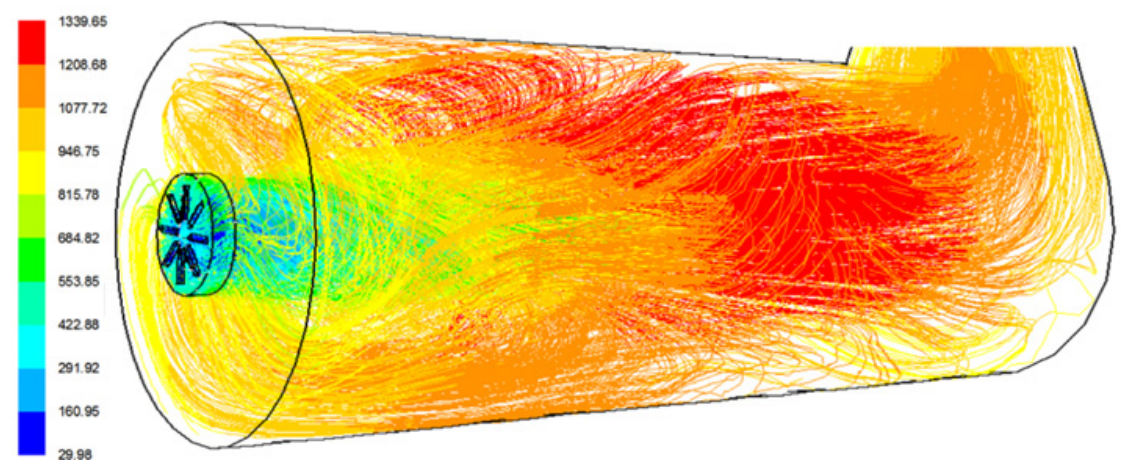

Figure 3. Pathlines in straight-flow fire-tube furnace with swirl burner colored according to the temperature.
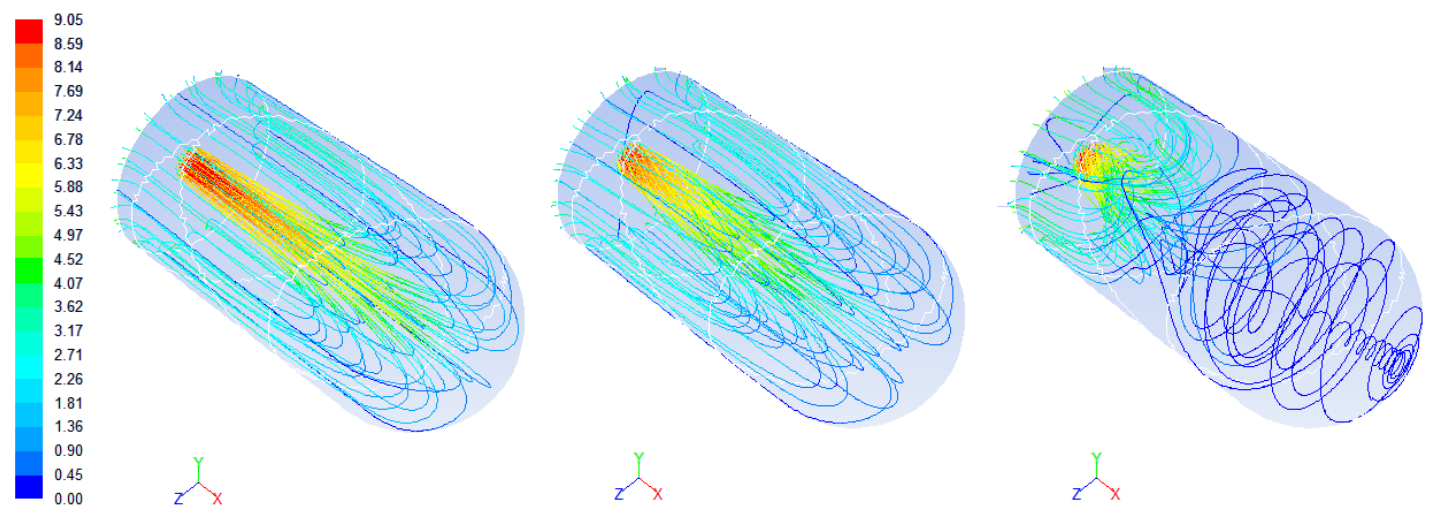

Figure 4. Pathlines in reversive fire-tube furnace with swirl burner colored according to the velocity magnitude (from left to right the twist parameter is increased).

of twist parameter force flame to be drawn into the convective pipes bank and entail an override of local heat fluxes in the vicinity of the burner (Fig. 4).

\section{Conclusion}

Using the software package ANSYS a detailed picture of the vortical aerodynamics in once-through fire tube and furnace with reversive flame is obtained. Various twist parameters of the fuel-air jet are considered. According to the simulation results it can be concluded: designers of rational burners should strive to fuel mixture preparing with minimal loss of useful energy, considering not only the mixing processes within the burner but in the combustion chamber.

In the fire-tube furnaces with reversive flame straight flow burners are preferred, as it contributes to a more reliable operation of the boiler due to uniform heat distribution along the length of the furnace. Moreover high values of burner twist parameter force reversive flame to be drawn into the convective pipes.

The reported study was partially supported by the Ministry of education and science of The Russian Federation, state order No. 13.948.2014/K. 


\section{References}

[1] S.A. Khaustov, A.S. Zavorin, R.N. Fisenko, Bulletin of Tomsk Polytechnic University 322, 43 (2013)

[2] A.S. Zavorin, S.A. Khaustov, N.A. Zaharushkin, IOP Conf. Series: Materials Science and Engineering 66, 012029 (2014)

[3] Moffatt Keith, IUTAM Symposium on Hamiltonian Dynamics, Vortex Structures, Turbulence (IUTAM Bookseries Vortex Dynamics) 6, p 1-10 (2008)

[4] A.V. Gil, A.V. Starchenko, Thermophysics and Aeromechanics 19, 503 (2012)

[5] S.A. Khaustov, A.S. Zavorin, R.N. Fisenko, Bulletin of Tomsk Polytechnic University 323, 43 (2013)

[6] T.S. Taylasheva, Bulletin of Tomsk Polytechnic University 314, 42 (2009)

[7] S.A. Khaustov, A.S. Zavorin, Industrial Power Engineering 2014 issue 1, 11 (2014) 